\title{
Postoperative cytokine levels and their predictive value in critical patients after major abdominal surgery: a retrospective cohort study
}

\author{
Yamin Yan", Peili Jin", Jingjing Lu, Dandan Cheng, Jiafeng Xu, Jiawen Yuan, Zhenghong Yu, Yan Hu \\ Nursing Department, Zhongshan Hospital, Fudan University, Shanghai, China \\ Contributions: (I) Conception and design: Y Hu, Z Yu; (II) Administrative support: Z Yu; (III) Provision of study materials or patients: Y Yan, Y Hu; \\ (IV) Collection and assembly of data: Y Yan, P Jin, J Xu, J Yuan; (V) Data analysis and interpretation: J Lu, D Cheng; (VI) Manuscript writing: All \\ authors; (VII) Final approval of manuscript: All authors. \\ "These authors contributed equally to this work. \\ Correspondence to: Yan Hu, BN. Head Nurse of the Surgery Department (ward 10), Zhongshan Hospital, Fudan University, No.180, Fenglin Road, \\ Xuhui District, Shanghai 200032, China. Email: hu.yan@zs-hospital.sh.cn; Zhenghong Yu, BN. Nursing Director of the Surgery Department, \\ Zhongshan Hospital, Fudan University, No.180, Fenglin Road, Xuhui District, Shanghai 200032, China. Email: yu.zhenghong@zs-hospital.sh.cn.
}

Backgrounda It remains uncertain as to what impact cytokine expression level has on patient outcomes. The association of serum levels of interleukin-1 $\beta$ (IL-1 $\beta$ ), IL-2, IL-6, IL-8, IL-10, tumor necrosis factor- $\alpha$ (TNF- $\alpha$ ), and procalcitonin with critically ill patient outcomes after major abdominal surgery still need to be explored.

Methods: From January 1, 2018 to June 30, 2019, a retrospective cohort study was conducted on patients admitted to the surgical intensive care unit (SICU). Levels of IL-1 $\beta$, IL-2, IL-6, IL-8, IL-10, TNF- $\alpha$, and procalcitonin were assessed in 1,228 patients undergoing major abdominal surgery with blood samples drawn within $24 \mathrm{~h}$ after surgery.

Results: Of the 1,228 patients admitted to the SICU for the first time, 1,152 survived and 76 patients died, with a mortality rate of $6.2 \%(76 / 1,228)$. The results of univariate and multivariate analyses revealed that non-survivors had higher levels of IL-1 $\beta$ (OR =2.438, $\mathrm{P}<0.001)$ and IL-2 (OR =1.561, P=0.006). Of 62 $(5.0 \%)$ readmitted to the SICU, the data of 59 were collected, and showed 46 patients survived and 13 died, giving a mortality rate of $22.0 \%$ (13/59), which was 3.5 times higher than the mortality rate during the first SICU admission. Serum IL-6 level associated with SICU readmission (OR =1.37, P=0.029). Furthermore, non-survivors had a longer SICU stay and higher rates of mechanical ventilation and continuous renal replacement therapy (CRRT).

Conclusions: High levels of IL-1 $\beta$ and IL-2 were associated with mortality, and a high level of IL-6 was a risk factor for SICU readmission in critically ill patients who underwent major abdominal surgery. The mortality rate was higher during the second SICU stay.

Keywords: Cytokine level; major abdominal surgery; critically ill patients; mortality; surgical intensive care unit readmission (SICU readmission)

Submitted Jul 02, 2021. Accepted for publication Nov 29, 2021.

doi: 10.21037/apm-21-2171

View this article at: https://dx.doi.org/10.21037/apm-21-2171

(c) Annals of Palliative Medicine. All rights reserved. 


\section{Introduction}

Abdominal surgery is a commonly conducted procedure which, because of progress in surgical and anesthetic techniques and perioperative management, has shown a marked decrease in mortality in recent times. Abdominal surgery carries a $1.5 \%$ to $40 \%$ mortality rate $(1,2)$. Intraoperative oxygen debt, including reduced systemic oxygen availability and the temporary interruption of blood flow to splanchnic organs, is directly correlated with patient outcomes (3-5). This may be because the surgical procedure and splanchnic ischemia can activate monocytes, macrophages, and endothelial cells, resulting in elevated blood interleukins' levels produced by these cells (6). Cytokine responses are correlated significantly with the magnitude of surgical stress, which reflected by the complexity of operation, duration of the surgery, and the amount of intraoperative blood loss and transfused (7).

An increasing number of studies have investigated whether interleukins are implicated in the pathogenesis of postoperative complications. The serum level of interleukin-6 (IL-6) was associated with outcomes and the severity of organ failure in critically ill patients $(8,9)$ and could be used to predict acute kidney injury (AKI) development. Increased postoperative IL-6 levels were associated with complications, specifically sepsis, reoperation, anastomotic dehiscence, and respiratory insufficiency (10), and elevated IL-6 and IL-8 levels were found in severe trauma patients who developed acute respiratory disease syndrome (ARDS) (11). Perioperative systemic inflammatory response syndrome (SIRS) is characterized by complex alterations in cytokine levels. The balance between TNF- $\alpha$ and IL-10 seemed to determine the occurrence of postoperative complications (7), and the perioperative assessment of C-reactive protein (CRP), IL6, IL-8, and IL-10 levels helped to predict and monitor postoperative atrial fibrillation (12).

Early identification of developing complications may facilitate clinical decision-making and improve their outcome (10). However, cytokine responses in critically ill patients after major abdominal surgery still underinvestigated. And the correlation of cytokine levels and clinical outcomes in these patients have not been described fully.

The aim of this study was to investigate serum cytokine levels in critically ill patients after major abdominal surgery. To this end, IL-1 $\beta$, IL-2, IL-6, IL-8, IL-10, TNF- $\alpha$, and procalcitonin were measured to further explore the association between these variables and clinical outcomes, such as mortality and surgical intensive care unit (SICU) readmission. Furthermore, we also evaluated the correlation between cytokine levels and readmission to the SICU. We present the following article in accordance with the STROBE reporting checklist (available at https://apm. amegroups.com/article/view/10.21037/apm-21-2171/rc).

\section{Methods}

\section{Setting and patients}

After the SICU admission, all the patients or their legal guardians provided written informed consent for the standard therapy and nursing care procedure. Prior to the analysis, all patient information was anonymized and deidentified.

This retrospective study was performed in a 50-bed surgery department and 28-bed SICU in a tertiary teaching hospital. Patients included all mechanically ventilated, critically ill patients who underwent emergency or elective major abdominal surgery. Patients were excluded if the data on demographic and clinical characteristics was missing, or information on cytokine levels after SICU admission was absent. A total of 1,228 patients were recruited in this study. All the enrolled patients received standard perioperative anesthetic management and surgery therapy.

\section{Data collection}

From January 1, 2018 to June 30, 2019, the following data were extracted: socio-demographic information, admitting diagnosis, type of surgery (emergency or elective), cytokine levels, and organ support therapy [including mechanical ventilation and continuous renal replacement therapy (CRRT)]. All the information was recorded by trained staffs during SICU stay.

The procedures detailed in this study were performed in accordance with the standards of the Declaration of Helsinki (as revised in 2013) and approved by the Ethics Committee on Human Experimentation of Zhongshan Hospital, Fudan University (No. B2020-107R).

\section{Cytokine measurements}

Blood samples were collected to test cytokines' level. Five milliliters of blood was obtained after postoperative venipuncture of a peripheral vein under sterile conditions 
within $24 \mathrm{~h}$ following the surgery. Blood was collected into sterile tubes, and kept at $-80{ }^{\circ} \mathrm{C}$ after centrifugation. Concentrations of the parameters of interest were measured through an IMMULITE 1000 Immunoassay System (Siemens, Berlin). Normal levels of detection were as follows: IL-1 $\beta$ : lower than $5 \mathrm{pg} / \mathrm{mL}$; IL-2: 223-710 U/mL; IL-6: lower than $3.4 \mathrm{pg} / \mathrm{mL}$; IL-8: lower than $62 \mathrm{pg} / \mathrm{mL}$; IL10: lower than $9.1 \mathrm{pg} / \mathrm{mL}$; TNF- $\alpha$ : lower than $8.1 \mathrm{pg} / \mathrm{mL}$; procalcitonin: lower than $0.5 \mathrm{ng} / \mathrm{mL}$.

\section{Outcomes}

The investigated outcomes included hospital mortality and several SICU-specific outcomes, including readmission rate, length of SICU stay, tracheostomy, receipt and duration of mechanical ventilation therapy, and receipt and duration of renal replacement therapy. Mechanical ventilation therapy included positive pressure ventilation via endotracheal tube or tracheostomy, and renal replacement therapy included all forms of CRRT and intermittent hemodialysis.

\section{Statistical analysis}

SPSS Statistics for Windows, Version 22.0 (Chicago, IL) was used for statistical analyses.

Data with nonnormal distributions was presented as medians and interquartile ranges (IQRs), and data with normal distributions was presented as means \pm standard deviations (SDs). The missing data was interpolated by average value. Independent sample $t$-test, Mann-WhitneyWilcoxon test and the Chi-square test were used for between-group comparisons, and descriptive statistics was used for outcome frequency. Multilevel mixed-effects logistic regression analysis was conducted for checking the relationship between cytokine levels and outcomes. The odds ratio (OR) and $95 \%$ confidence intervals (CI) were reported. Those variables that showed significance in univariate analysis were also included in multiple logistic regression analysis to examine independent effect. Overall survival curves were plotted by the Kaplan-Meier analysis. A $P$ value $<0.05$ indicated statistical significance.

\section{Results}

\section{Demographic and clinical characteristics}

A total of 1,228 patients who presented between January 1, 2018 and June 30, 2019, were included. The overall mortality rate was $6.2 \%$ (1,152 patients survived, and 76 died). The mortality rate of patients undergoing emergency surgery was $11.1 \%$ (69/621), which was much higher than that of those undergoing elective surgery $(1.0 \%)$. However, the mortality rate of cancer patients was much lower than that of noncancer patients ( $2.8 \%$ vs. $8.7 \%)$. Length of SICU stay and mechanical ventilation in the non-surviving group were longer. And the rates of SICU readmission, mechanical ventilation, CRRT therapy, tracheotomy, and emergency surgery were higher. Demographic and clinical characteristics are shown in Table 1.

\section{Cytokine levels increased in non-survivors}

To investigate the influence of cytokine levels on hospital mortality, we assessed the differences in cytokine levels. The results showed that non-survivors had higher levels of IL-1 $\beta$, IL-2, IL-6, IL-8, IL-10, TNF- $\alpha$, and procalcitonin (Table 2). A significant correlation between serum IL$1 \beta$ and IL-2 levels and mortality. However, no significant differences were observed in IL-6, IL-8, IL-10, TNF- $\alpha$, or procalcitonin levels and mortality (Table 3).

\section{IL-6 levels increased in patients readmitted to the SICU}

Of the 1,228 patients, 62 were readmitted to the SICU, and the readmission rate was $5.0 \%$. The readmitted group patients had higher rates of mechanical ventilation therapy, CRRT therapy, and emergency surgery.

Higher levels of IL-2, IL-6, IL-10, TNF- $\alpha$, and procalcitonin were found in readmitted patients than in the patients who were not readmitted (Table 4). Univariate analyses showed that higher IL-6 concentration was correlated with higher SICU readmission rate. However, no such correlation was found in multivariate analysis (Table 5).

\section{Correlation between cytokine levels and outcomes in patients readmitted to the SICU}

Among the 62 patients readmitted to the SICU, 59 had their cytokine levels tested during their second stay. Overall, 46 patients survived, and 13 died, giving a mortality rate of $22.0 \%(13 / 59)$, which was much higher than that during the first SICU stay $(6.2 \%)$. Among the 59 patients readmitted to the SICU, four were admitted a third time, with a rate of third SICU admission of $6.8 \%$. Of these, two patients died, and the mortality rate was $50.0 \%(2 / 4)$.

To explore outcomes and risk factors, we assessed the 
Table 1 Baseline patient characteristics $(\mathrm{n}=1,228)$

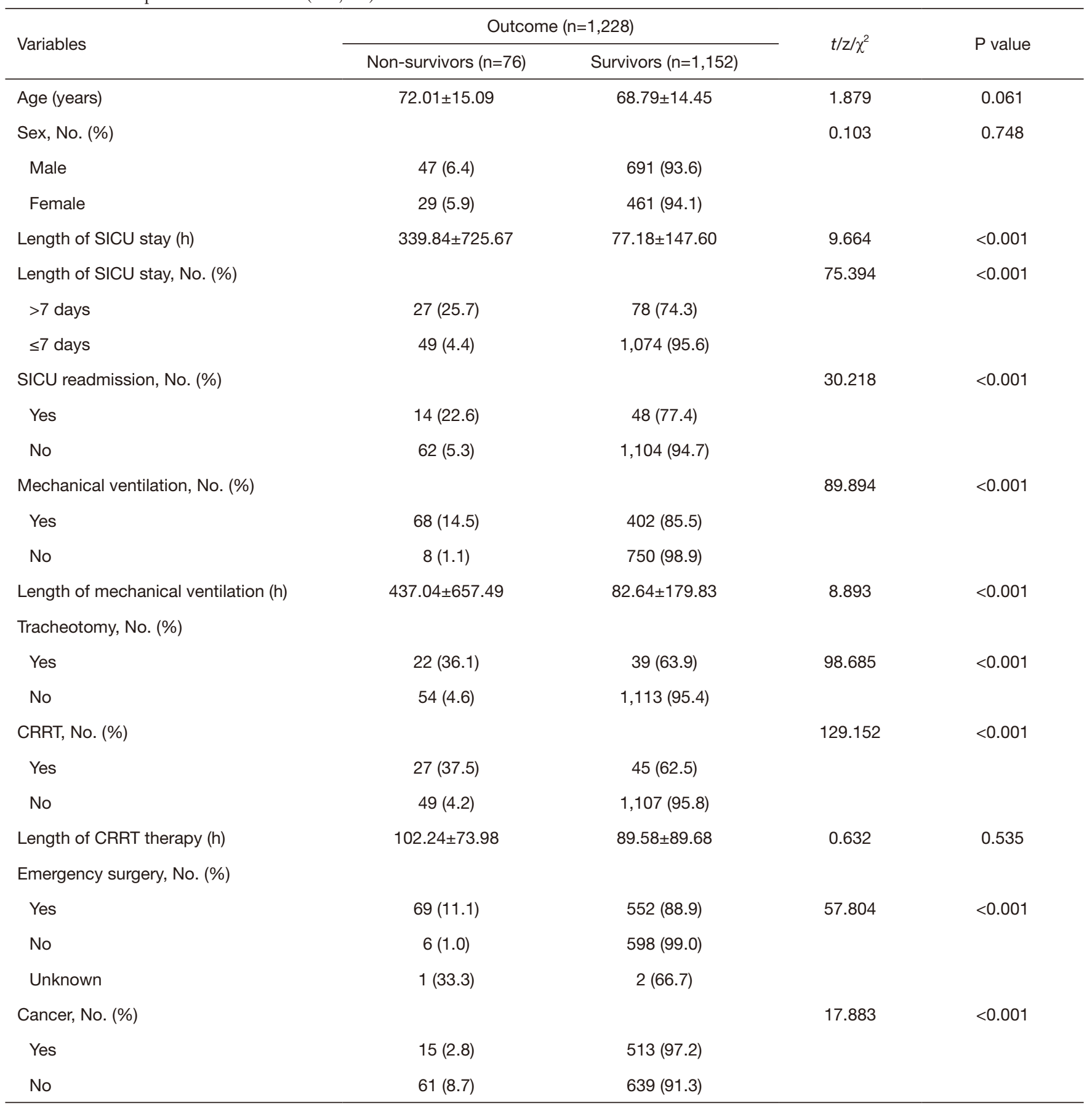

SICU, surgical intensive care unit; CRRT, continuous renal replacement therapy. 
Table 2 Cytokine levels in survivors and non-survivors $(\mathrm{n}=1,228)$

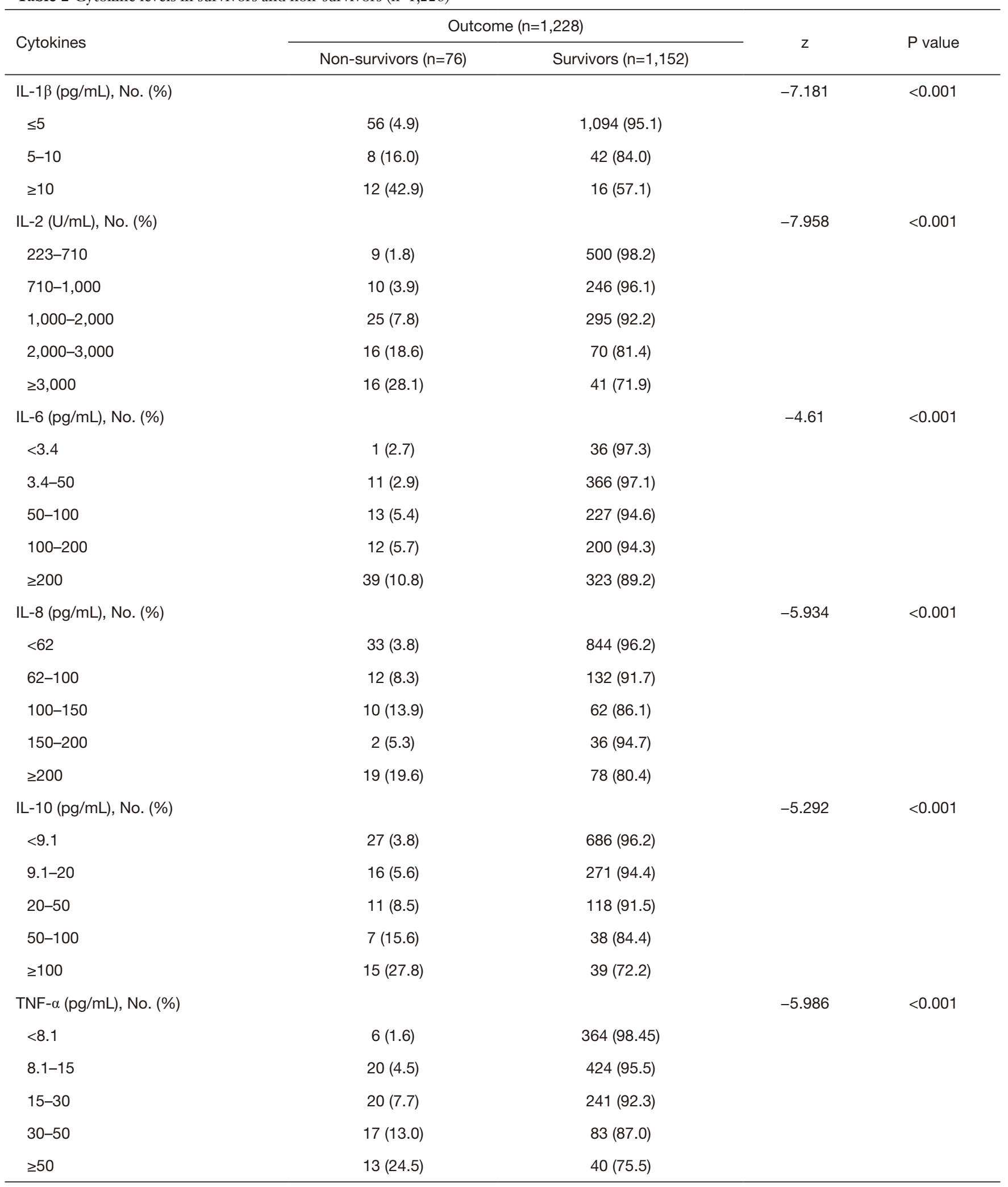

Table 2 (continued) 
Table 2 (continued)

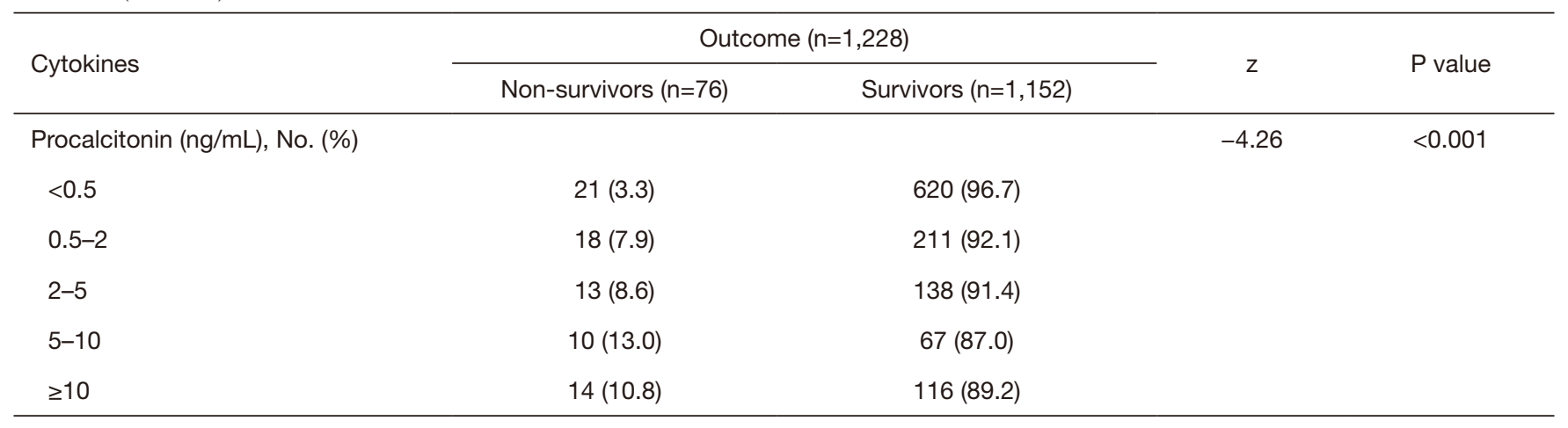

IL, interleukin; TNF- $\alpha$, tumor necrosis factor- $\alpha$.

Table 3 Analysis of factors associated with patient outcomes

\begin{tabular}{|c|c|c|c|c|c|}
\hline Variables & $\beta$ & SE & $P$ value & OR & $95 \% \mathrm{Cl}$ \\
\hline \multicolumn{6}{|l|}{ Univariate analysis } \\
\hline Sex & -0.074 & 0.317 & 0.816 & 0.929 & $(0.499,1.730)$ \\
\hline Length of SICU stay & -0.938 & 0.344 & 0.006 & 0.391 & $(0.199,0.767)$ \\
\hline SICU readmission & 1.069 & 0.435 & 0.014 & 2.911 & $(1.241,6.83)$ \\
\hline CRRT & 1.304 & 0.379 & 0.001 & 3.683 & $(1.752,7.743)$ \\
\hline IL1 & 0.891 & 0.208 & $<0.001$ & 2.438 & $(1.622,3.666)$ \\
\hline IL2 & 0.445 & 0.162 & 0.006 & 1.561 & $(1.137,2.142)$ \\
\hline IL6 & -0.027 & 0.148 & 0.854 & 0.973 & $(0.728,1.300)$ \\
\hline TNF- $\alpha$ & -0.098 & 0.176 & 0.579 & 0.907 & $(0.642,1.281)$ \\
\hline Procalcitonin & -0.076 & 0.111 & 0.493 & 0.927 & $(0.746,1.151)$ \\
\hline \multicolumn{6}{|l|}{ Multivariate analysis } \\
\hline Length of SICU stay & -0.928 & 0.321 & 0.004 & 0.395 & $(0.211,0.741)$ \\
\hline SICU readmission & 1.201 & 0.391 & 0.002 & 3.323 & $(1.545,7.149)$ \\
\hline Mechanical ventilation & 1.781 & 0.413 & $<0.001$ & 5.934 & $(2.640,13.338)$ \\
\hline CRRT & 1.203 & 0.353 & 0.001 & 3.329 & $(1.667,6.650)$ \\
\hline IL1 & 0.814 & 0.169 & $<0.001$ & 2.257 & $(1.620,3.144)$ \\
\hline
\end{tabular}

SICU, surgical intensive care unit; CRRT, continuous renal replacement therapy; IL, interleukin; TNF- $\alpha$, tumor necrosis factor- $\alpha$. 
Table 4 Cytokine levels in patients with or without SICU readmission $(n=1,228)$

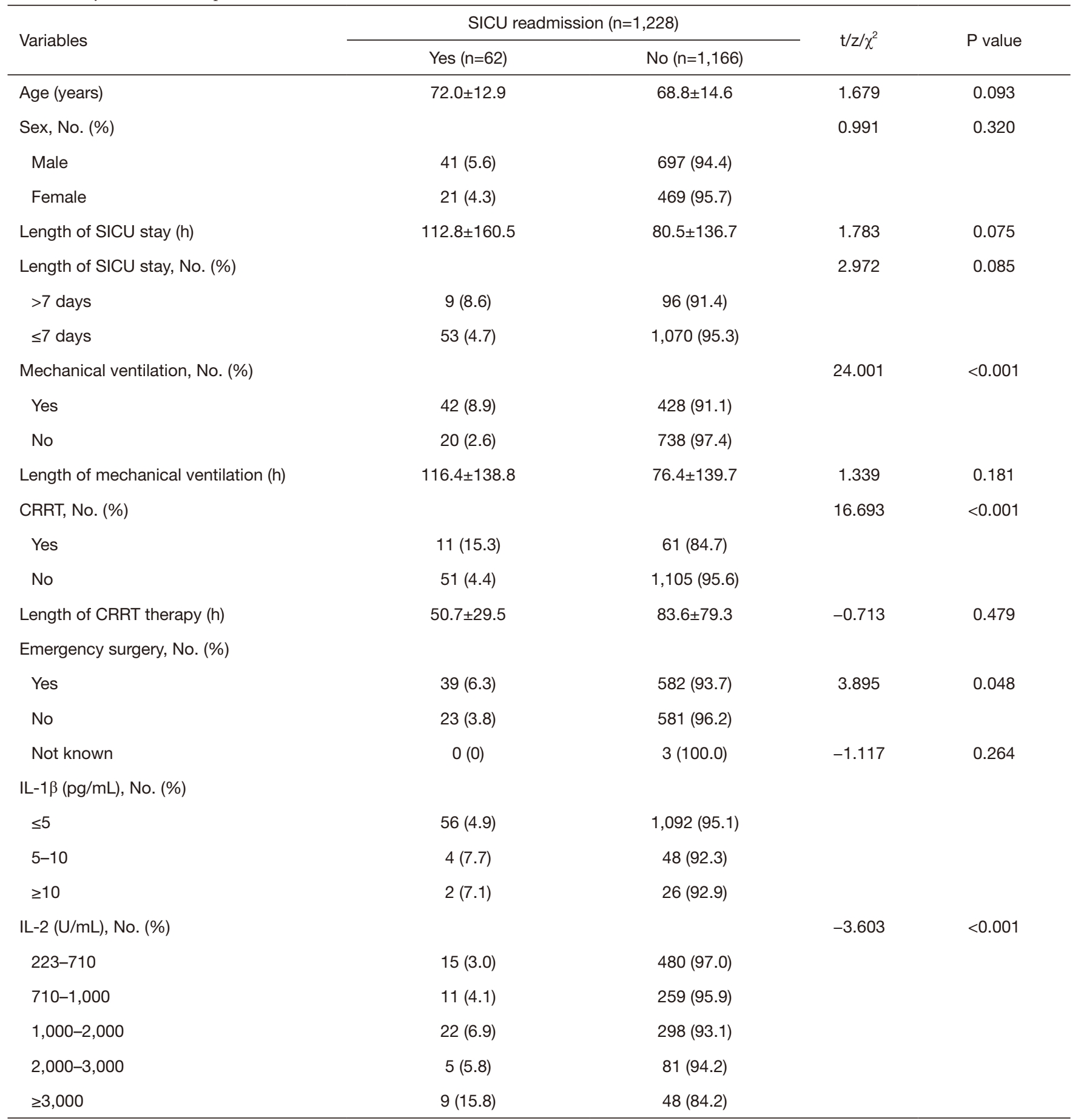

Table 4 (continued) 
Table 4 (continued)

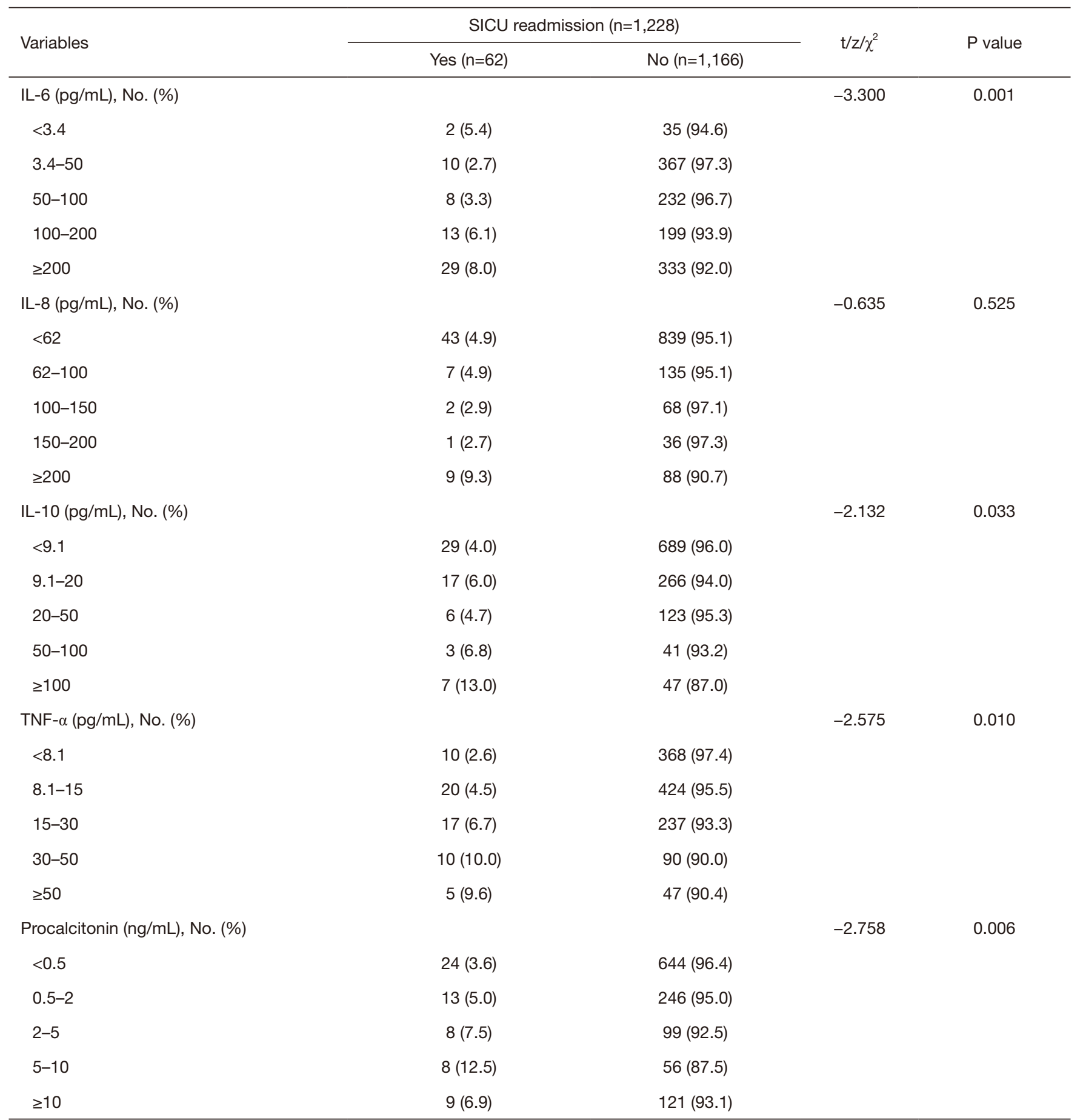

SICU, surgical intensive care unit; CRRT, continuous renal replacement therapy; IL, interleukin; TNF- $\alpha$, tumor necrosis factor- $\alpha$. 
Table 5 Analysis of factors associated with SICU readmission

\begin{tabular}{|c|c|c|c|c|c|}
\hline Variables & $\beta$ & SE & $P$ value & OR & $95 \% \mathrm{Cl}$ \\
\hline Sex & 0.075 & 0.309 & 0.809 & 1.077 & $(0.588,1.974)$ \\
\hline Length of SICU stay & -0.056 & 0.444 & 0.899 & 0.945 & $(0.396,2.255)$ \\
\hline Mechanical ventilation & 1.075 & 0.354 & 0.002 & 2.930 & $(1.465,5.858)$ \\
\hline $\mathrm{IL}-1$ & -0.159 & 0.34 & 0.640 & 0.853 & $(0.438,1.662)$ \\
\hline IL-2 & 0.092 & 0.17 & 0.589 & 1.096 & $(0.786,1.529)$ \\
\hline IL-6 & 0.315 & 0.145 & 0.029 & 1.37 & $(1.032,1.819)$ \\
\hline $\mathrm{IL}-8$ & -0.125 & 0.15 & 0.405 & 0.883 & $(0.658,1.184)$ \\
\hline Procalcitonin & -0.048 & 0.119 & 0.684 & 0.953 & $(0.755,1.203)$ \\
\hline \multicolumn{6}{|l|}{ Multivariate analysis } \\
\hline Mechanical ventilation & 1.012 & 0.298 & 0.001 & 2.75 & $(1.533,4.933)$ \\
\hline CRRT & 0.824 & 0.376 & 0.028 & 2.279 & $(1.091,4.762)$ \\
\hline IL6 & 0.208 & 0.114 & 0.068 & 1.231 & $(0.984,1.539)$ \\
\hline
\end{tabular}

SICU, surgical intensive care unit; CRRT, continuous renal replacement therapy; IL, interleukin; TNF- $\alpha$, tumor necrosis factor- $\alpha$.

differences in cytokine levels between survivors and nonsurvivors. Non-survivors had higher levels of IL-6 than survivors, but no correlation was noted in other cytokines (Table 6).

\section{Prognostic values of the cytokines}

Totally, 76 of the 1,228 patients in this study died, and the overall survival rate was significantly lower for patients with higher levels of IL-1 $\beta$, IL-2, IL-6, IL-8, IL-10, TNF- $\alpha$, and procalcitonin (Figure 1).

\section{Discussion}

This study shows that as the number of SICU admissions increased, mortality also increased $(6.2 \%<22.0 \%<50.0 \%)$. Major surgery leads to the release of pro- and antiinflammatory cytokines, and patients with higher levels of IL- $1 \beta$ and IL- 2 within the first $24 \mathrm{~h}$ after operation had an increased mortality rate, while those with a high level of IL-6 had an increased SICU readmission rate.

Surgical trauma can cause increased pro-inflammatory cytokines expression in circulation with associated postoperative morbidity (13). Kvarnström et al. reported that during colorectal surgery, there was an inflammatory response with elevated levels of pro-inflammatory cytokines, and in the early postoperative period, the release of pro-inflammatory interleukins (IL-6 and IL-8) and anti-inflammatory interleukins (IL-10) increased (14). In another study, IL-6, CRP, and procalcitonin expression levels were evaluated on the first postoperative day in patients received major gastrointestinal and gynecologic tumor resection. The results also showed that after surgery, the patients who developed sepsis within 5 days had higher levels of IL-6 on the first postoperative day compared to those who did not experience sepsis (15). High levels of this cytokine are considered to be a negative prognostic factor for disease-free intervals and overall survival (16), and our results showed they also correlate positively with SICU readmission rate. Although univariate analyses only showed IL-6 level $(\mathrm{OR}=1.37, \mathrm{P}=0.029)$ correlated with SICU readmission rate, the rate was higher in patients with high levels of IL-2, IL-6, IL-10, TNF- $\alpha$, and procalcitonin. These results suggest cytokine levels influence the outcomes 
Table 6 Outcomes of patients readmitted to SICU

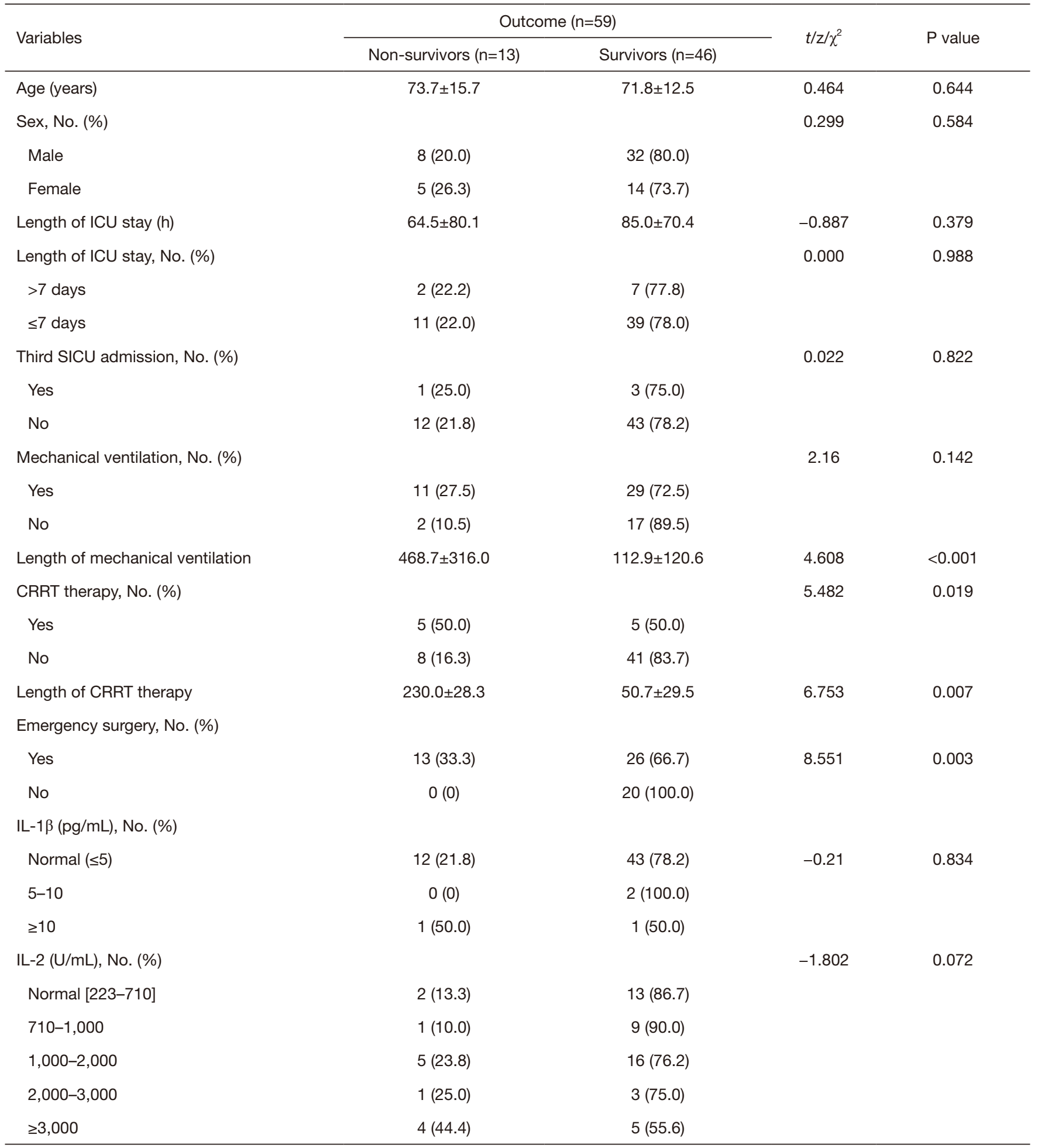

Table 6 (continued) 
Table 6 (continued)

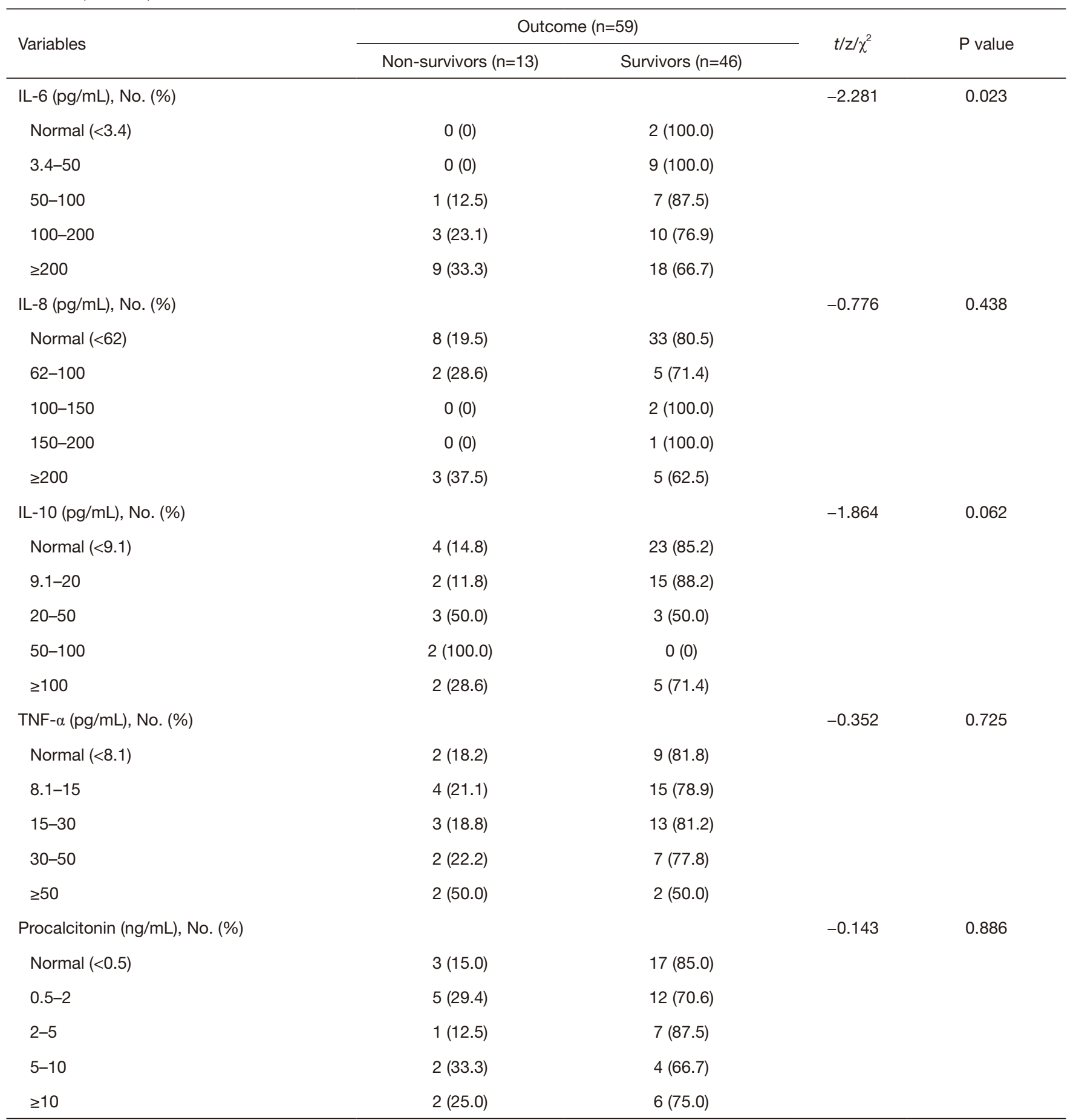

SICU, surgical intensive care unit; CRRT, continuous renal replacement therapy; IL, interleukin; TNF- $\alpha$, tumor necrosis factor- $\alpha$. 

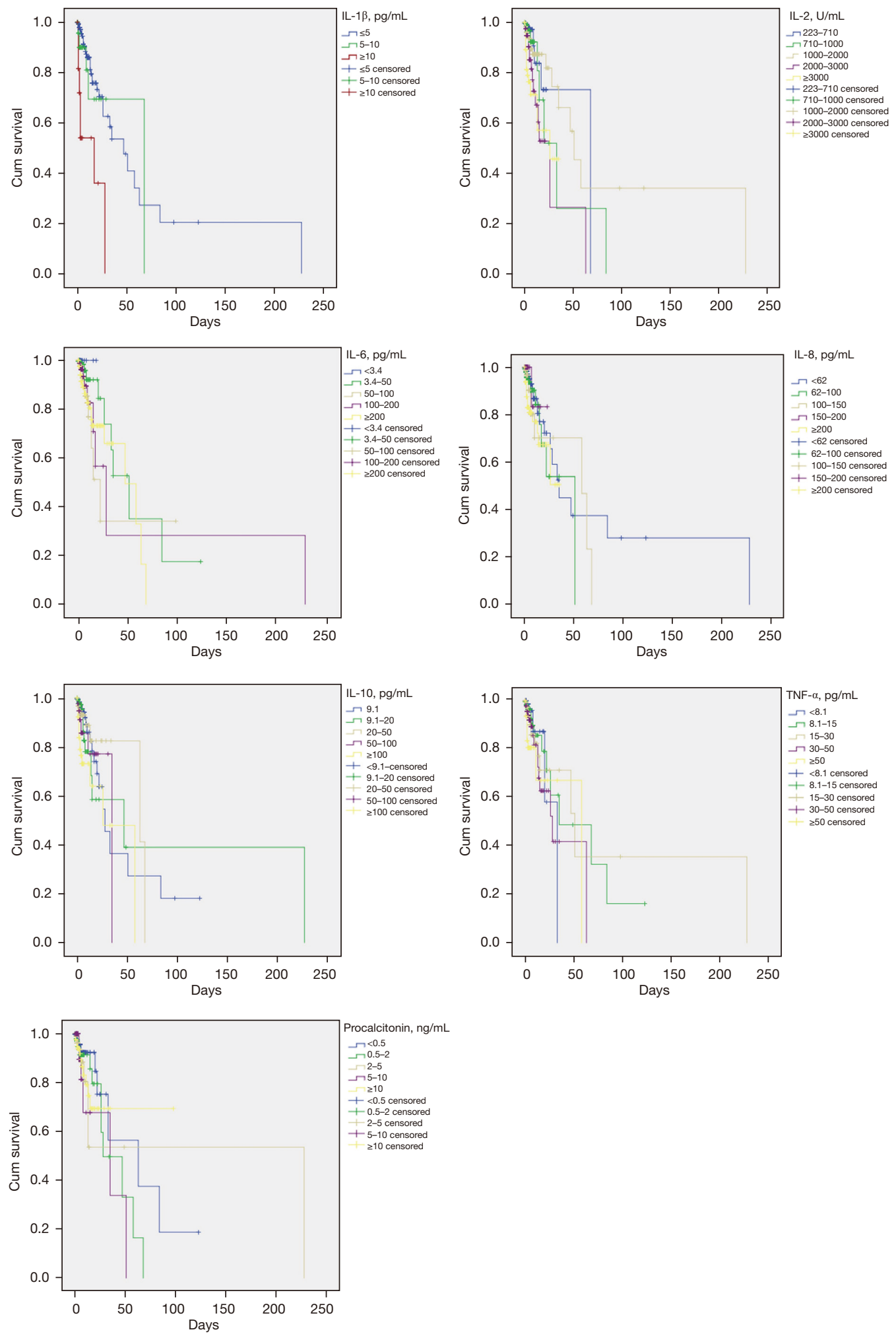

Figure 1 Association between overall survival and IL-1 $\beta$, IL-2, IL-6, IL-8, IL-10, TNF- $\alpha$, and procalcitonin levels in 1,228 patients. IL, interleukin; TNF- $\alpha$, tumor necrosis factor- $\alpha$. 
of critically ill patients undergoing surgery. Further, similar results were noted during the second SICU stay, where the IL-6 level correlated positively with patient outcomes $(\mathrm{z}=-2.281, \mathrm{P}=0.023)$.

Major abdominal surgery is a common procedure and is associated with a high complication rate, and one method to improve the early detection of complications is to use inflammatory markers. While SIRS pathogenesis may mediated by a variety of pro- and anti-inflammatory mediators $(17,18)$, the mechanism mediating this response is not straightforward (10). In short, tissue damage induces the proliferation of immunocompetent cells, such as monocytes, macrophages, dendritic cells, lymphocytes, and neutrophils (19), which triggers the production of cytokines and chemokines. In this study, higher levels of IL-1 $\beta$, IL-2, IL-6, IL-8, IL-10, TNF- $\alpha$, and procalcitonin in non-survivors were observed, and univariate and multivariate analyses showed the influence of IL-1 $\beta$ $(\mathrm{OR}=2.438, \mathrm{P}<0.001)$ and $\mathrm{IL}-2(\mathrm{OR}=1.561, \mathrm{P}=0.006)$ was significant. These findings are in agreement with those of other researches $(20,21)$. The role of the IL-1 family in the pathogenesis of anti-inflammation has been previously explored (22). IL-1 $\beta$ is a key regulator of the IL-1 family by playing a role in determining inflammation, and is currently being examined in septic patients (23). IL-2 is a key cytokine involved in the immune response, and its regulation can promote the differentiation of $\mathrm{T}$ cells and enhance the cytotoxic effect (24). IL-2 was also positively associated with delirium in patients undergoing coronary artery bypass graft surgery (25). From these results, we can infer that IL-1 $\beta$ and IL-2 have distinctive informative value in detecting the state of local immunity in patients after major abdominal surgery. In addition, the anesthesia maintenance technique during surgery may also influence the inflammatory response. Sevoflurane has been demonstrated to suppress the production of IL-6 and IL- 8 but not IL-10 and IL-1 receptor antagonists after abdominal surgery (26), while lower plasma levels of both IL-6 and IL-8 were observed after aortic declamping under intravenous anesthesia with propofol, which may promote the production of anti-inflammatory cytokines (27). However, we failed to collect information on the anesthesia technique in this study, and further investigation is required to explore this association.

As shown in Tables 1 and 4, length of SICU stay, received emergency surgery, mechanical ventilation and CRRT therapy were associated with mortality. Meanwhile, received emergency surgery, mechanical ventilation and CRRT therapy were also associated with SICU readmission. It is speculated that these factors may correlated positively with disease severity and degree of organ dysfunction. Some previous studies have found that in non-septic patients, cytokines are independent outcome predictors of disease severity scores, including the acute physiology and chronic health evaluation (APACHE II) and sequential organ failure assessment (SOFA) scores $(28,29)$.

\section{Conclusions}

In conclusion, the mortality rate in patients undergoing major abdominal surgery increased with the number of SICU admissions and cytokine levels. IL- $1 \beta$ and IL-2, were associated with patient outcomes, while the IL-6 level was associated with the SICU readmission rate. In short, IL$1 \beta$, IL-2, and IL-6 levels could add value in early clinical decision-making for patients undergoing major abdominal surgery. Further study is required regarding therapeutic interventions targeting cytokine signaling networks to modify inflammatory and autoimmune diseases as well as cancer.

\section{Limitations}

The limitations of this study are as follows. First, we detected cytokines only within $24 \mathrm{~h}$ after the operation. The time between surgery and the collection of blood samples was somewhat variable among patients due to variations in surgery starting times, and dynamic cytokine levels during the early phase may have influenced the results. Therefore, sequential assessments of cytokine level changes may provide further evidence for the associations. Second, the anesthesia maintenance technique was not analyzed, and this may also influence the inflammatory response during surgery. Third, this was a single-center retrospective study in patients after major abdominal surgery, and multi-center prospective studies are required to verify the results.

\section{Acknowledgments}

The authors sincerely thank Jian Gao for guiding collection of the data and the statistical analysis, and thank Yuxia Zhang for guidance in writing the manuscript and data checking.

Funding: This work was supported by the Youth Program of Zhongshan Hospital, Fudan University (No. 2019ZSQN01), and the Fuxing Nursing Program of Fudan 
University (No. FNF201945; No. FNF202007).

\section{Footnote}

Reporting Checklist: The authors have completed the STROBE reporting checklist. Available at https://apm. amegroups.com/article/view/10.21037/apm-21-2171/rc

Data Sharing Statement: Available at https://apm.amegroups. com/article/view/10.21037/apm-21-2171/dss

Conflicts of Interest: All authors have completed the ICMJE uniform disclosure form (available at https://apm. amegroups.com/article/view/10.21037/apm-21-2171/coif). The authors have no conflicts of interest to declare.

Ethical Statement: The authors are accountable for all aspects of the work in ensuring that questions related to the accuracy or integrity of any part of the work are appropriately investigated and resolved. The procedures detailed in this study were performed in accordance with the standards of the Declaration of Helsinki (as revised in 2013) and approved by the Ethics Committee on Human Experimentation of Zhongshan Hospital, Fudan University (No. B2020-107R). All the patients or their legal guardians provided written informed consent for the standard therapy and nursing care procedure.

Open Access Statement: This is an Open Access article distributed in accordance with the Creative Commons Attribution-NonCommercial-NoDerivs 4.0 International License (CC BY-NC-ND 4.0), which permits the noncommercial replication and distribution of the article with the strict proviso that no changes or edits are made and the original work is properly cited (including links to both the formal publication through the relevant DOI and the license). See: https://creativecommons.org/licenses/by-nc-nd/4.0/.

\section{References}

1. International Surgical Outcomes Study group. Global patient outcomes after elective surgery: prospective cohort study in 27 low-, middle- and high-income countries. Br J Anaesth 2016;117:601-9.

2. Finks JF, Osborne NH, Birkmeyer JD. Trends in hospital volume and operative mortality for high-risk surgery. $\mathrm{N}$ Engl J Med 2011;364:2128-37.

3. Shoemaker WC, Appel PL, Kram HB. Tissue oxygen debt as a determinant of lethal and nonlethal postoperative organ failure. Crit Care Med 1988;16:1117-20.

4. Cain SM. Peripheral oxygen uptake and delivery in health and disease. Clin Chest Med 1983;4:139-48.

5. Boyd O, Grounds RM, Bennett ED. A randomized clinical trial of the effect of deliberate perioperative increase of oxygen delivery on mortality in high-risk surgical patients. JAMA 1993;270:2699-707.

6. Metinko AP, Kunkel SL, Standiford TJ, et al. Anoxiahyperoxia induces monocyte-derived interleukin-8. J Clin Invest 1992;90:791-8.

7. Dimopoulou I, Armaganidis A, Douka E, et al. Tumour necrosis factor-alpha (TNFalpha) and interleukin-10 are crucial mediators in post-operative systemic inflammatory response and determine the occurrence of complications after major abdominal surgery. Cytokine 2007;37:55-61.

8. Shimazui T, Matsumura Y, Nakada TA, et al. Serum levels of interleukin-6 may predict organ dysfunction earlier than SOFA score. Acute Med Surg 2017;4:255-61.

9. Quispe E Á, Li XM, Yi H. Comparison and relationship of thyroid hormones, IL-6, IL-10 and albumin as mortality predictors in case-mix critically ill patients. Cytokine 2016;81:94-100.

10. Rettig TC, Verwijmeren L, Dijkstra IM, et al. Postoperative Interleukin-6 Level and Early Detection of Complications After Elective Major Abdominal Surgery. Ann Surg 2016;263:1207-12.

11. Meade P, Shoemaker WC, Donnelly TJ, et al. Temporal patterns of hemodynamics, oxygen transport, cytokine activity, and complement activity in the development of adult respiratory distress syndrome after severe injury. J Trauma 1994;36:651-7.

12. Weymann A, Popov AF, Sabashnikov A, et al. Baseline and postoperative levels of C-reactive protein and interleukins as inflammatory predictors of atrial fibrillation following cardiac surgery: a systematic review and meta-analysis. Kardiol Pol 2018;76:440-51.

13. Baker EA, El-Gaddal S, Williams L, et al. Profiles of inflammatory cytokines following colorectal surgery: relationship with wound healing and outcome. Wound Repair Regen 2006;14:566-72.

14. Kvarnström AL, Sarbinowski RT, Bengtson JP, et al. Complement activation and interleukin response in major abdominal surgery. Scand J Immunol 2012;75:510-6.

15. Mokart D, Merlin M, Sannini A, et al. Procalcitonin, interleukin 6 and systemic inflammatory response syndrome (SIRS): early markers of postoperative sepsis after major surgery. Br J Anaesth 2005;94:767-73. 
16. Asadullah K, Sterry W, Volk HD. Interleukin-10 therapy-review of a new approach. Pharmacol Rev 2003;55:241-69.

17. Jekarl DW, Kim KS, Lee S, et al. Cytokine and molecular networks in sepsis cases: a network biology approach. Eur Cytokine Netw 2018;29:103-11.

18. Matsumoto H, Ogura H, Shimizu K, et al. The clinical importance of a cytokine network in the acute phase of sepsis. Sci Rep 2018;8:13995.

19. Castellheim A, Brekke OL, Espevik T, et al. Innate immune responses to danger signals in systemic inflammatory response syndrome and sepsis. Scand J Immunol 2009;69:479-91.

20. Jordan SC, Choi J, Kim I, et al. Interleukin-6, A Cytokine Critical to Mediation of Inflammation, Autoimmunity and Allograft Rejection: Therapeutic Implications of IL-6 Receptor Blockade. Transplantation 2017;101:32-44.

21. Heper Y, Akalin EH, Mistik R, et al. Evaluation of serum C-reactive protein, procalcitonin, tumor necrosis factor alpha, and interleukin-10 levels as diagnostic and prognostic parameters in patients with communityacquired sepsis, severe sepsis, and septic shock. Eur J Clin Microbiol Infect Dis 2006;25:481-91.

22. Franza L, Carusi V, Altamura S, et al. Interrelationship between inflammatory cytokines (IL-1, IL-6, IL-33, IL37) and acquired immunity. J Biol Regul Homeost Agents 2019;33:1321-6.

23. Ge Y, Huang M, Yao YM. Recent advances in the biology

Cite this article as: Yan Y, Jin P, Lu J, Cheng D, Xu J, Yuan J, $\mathrm{Yu} \mathrm{Z}, \mathrm{Hu}$ Y. Postoperative cytokine levels and their predictive value in critical patients after major abdominal surgery: a retrospective cohort study. Ann Palliat Med 2022;11(1):1-15. doi: 10.21037/apm-21-2171 of IL-1 family cytokines and their potential roles in development of sepsis. Cytokine Growth Factor Rev 2019;45:24-34.

24. Huang C, Zhou L, Chang X, et al. B7-H3, B7-H4, Foxp3 and IL-2 expression in cervical cancer: Associations with patient outcome and clinical significance. Oncol Rep 2016;35:2183-90.

25. Kazmierski J, Banys A, Latek J, et al. Raised IL-2 and TNF- $\alpha$ concentrations are associated with postoperative delirium in patients undergoing coronary-artery bypass graft surgery. Int Psychogeriatr 2014;26:845-55.

26. Crozier TA, Müller JE, Quittkat D, et al. Effect of anaesthesia on the cytokine responses to abdominal surgery. Br J Anaesth 1994;72:280-5.

27. Kawamura T, Kadosaki M, Nara N, et al. Effects of sevoflurane on cytokine balance in patients undergoing coronary artery bypass graft surgery. J Cardiothorac Vasc Anesth 2006;20:503-8.

28. Rodríguez-Gaspar M, Santolaria F, Jarque-López A, et al. Prognostic value of cytokines in SIRS general medical patients. Cytokine 2001;15:232-6.

29. Dimopoulou I, Orfanos S, Kotanidou A, et al. Plasma pro- and anti-inflammatory cytokine levels and outcome prediction in unselected critically ill patients. Cytokine 2008;41:263-7.

(English Language Editor: B. Draper) 